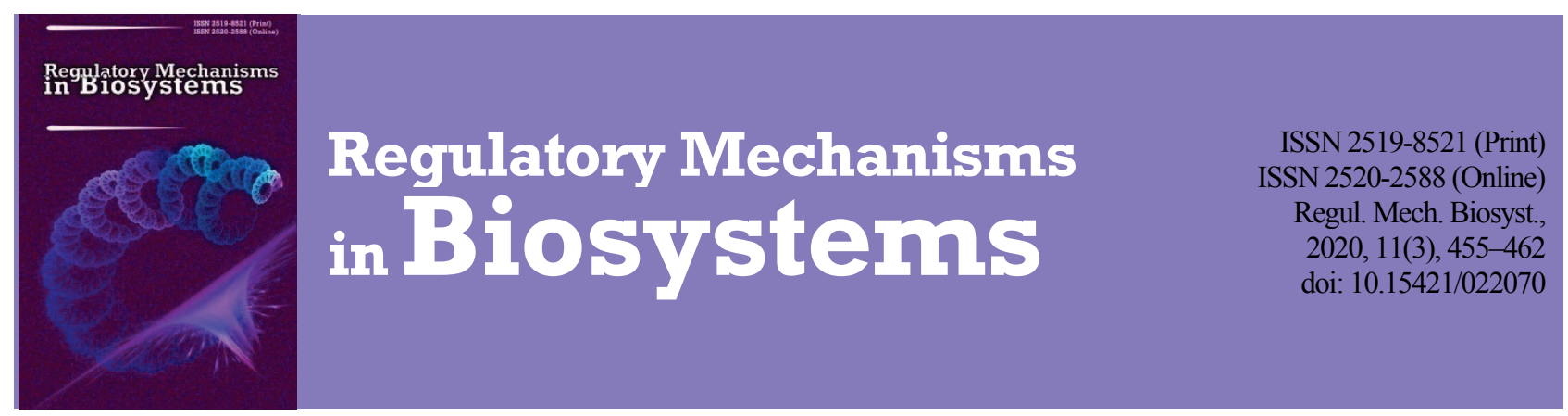

\title{
Potential role of cytoplasmic protein binding to erythrocyte membrane in counteracting oxidative and metabolic stress
}

\author{
O. I. Dotsenko, I. V. Mykutska, G. V. Taradina, Z. O. Boiarska \\ Vasyl' Stus Donetsk National University, Vinnytsia, Ukraine
}

Article info
Received 16.07 .2020
Received in revised form
14.08 .2020
Accepted 15.08 .2020

Vasyl' Stus Donetsk

National University,

600-richya st, 21

Tel.: +38-093-724-66-10

E-mail:dots_on@ukr.net
Vinnytsia, 21021, Ukraine

\begin{abstract}
Dotsenko, O. I., Mykutska, I. V., Taradina, G. V., \& Boiarska, Z. O. (2020). Potential role of cytoplasmic protein binding to erythrocyte membrane in counteracting oxidative and metabolic stress. Regulatory Mechanisms in Biosystems, $11(3), 455-462$. doi:10.15421/022070
\end{abstract}

The ability of protein to reversibly bind with membrane components is considered to be one of the oldest mechanisms of cell response to external stimuli. Erythrocytes have a well-developed mechanism of an adaptive response involving sorption-desorption processes, e.g. interactions of key glycolytic enzymes and hemoglobin with band 3 protein. A few publications have shown that under oxidative stress, cytoplasmic enzymes such as catalase, glutathione peroxidase and peroxiredoxin bind to the erythrocyte membrane. The present work is a continuation of research in this direction to determine the causes and consequences of the interaction of cytoplasmic proteins with the membrane under conditions of oxidative stress and different glucose content. Human erythrocytes were incubated for five hours at $20^{\circ} \mathrm{C}$ in an oxidizing medium of $\mathrm{AscH}-1 \cdot 10^{-4} \mathrm{M}, \mathrm{Cu}^{2+}-5 \cdot 10^{-6} \mathrm{M}$ with different glucose content $(0-$ $8 \mathrm{mM}$ ). Dynamic changes in the accumulation of membrane-bound hemoglobin, the distribution of ligand forms of hemoglobin in the cytoplasmic and membrane-bound fractions, the activity of membrane-associated and cytoplasmic forms of $\mathrm{Cu} / \mathrm{Zn}$ superoxide dismutase (SOD1) and catalase, $\mathrm{H}_{2} \mathrm{O}_{2}$ content in extracellular and intracellular media were recorded. It was shown that binding of catalase and SOD1 to the erythrocyte membrane is initiated by oxidative stress and is a physiological function aimed at complete inactivation of extracellular and $\mathrm{H}_{2} \mathrm{O}_{2}$ and protection against their entry into the cell. It was shown that under conditions of glucose depletion and oxidative loading, catalase and SOD1 bind to the erythrocyte membrane, leading to inactivation of these enzymes. Membrane-bound hemoglobin was higher in cells incubated under these conditions than in glucose experiments. Glucose introduced into the incubation medium in an amount 4-8 mM causes complete binding of SOD1 to the membrane of erythrocytes, by involving it in the processes of casein kinase stabilization and glycolytic fluxes regulation. With mild oxidation, the amount of hemoglobin bound to the membrane does not change, indicating the presence of certain binding sites for hemoglobin with membrane proteins. We show that the activity of membrane-bound SOD1 along with the content of ligand forms in the composition of membrane-bound hemoglobin are informative indicators of the metabolic and redox state of erythrocytes.

Keywords: oxidative stress; catalase; superoxide dismutase; ascorbate; copper ions; ligand forms of hemoglobin; membrane-bound hemoglobin.

\section{Introduction}

The human erythrocyte (RBC) membrane plays a key role in providing and regulating the physiological activity of these cells. It is a complex structure composed by a lipid bilayer and cytoskeleton proteins tethered together by transmembrane proteins such as band 3 protein (CDB3) and glycophorins. Enzymes bound to the cytoplasmic surface of the RBC membrane may represent an extension of membrane organization into the cytoplasm. The ability of proteins to bind back to membrane components is considered to be one of the oldest mechanisms of response to external influences (Kosmachevskaya et al., 2019). As a rule, the binding of enzymes to membranes leads to a decrease in their activity and is directly dependent on the energy charge of the cell. By binding enzymes, the cell can change its metabolism in seconds, while the realization of the response via changes in gene expression is more time consuming (Kosmachevskaya et al., 2019). RBCs have a well-developed mechanism for forming an adaptive response involving sorption-desorption processes. An example of reversible binding is the interaction of key glycolytic enzymes with CDB3 (Puchulu-Campanella et al., 2013; Chu et al., 2016; Kosmachevskaya et al., 2019). Aldolase and phosphofructokinase and glyceraldehyde3-phosphate dehydrogenase are enzymes associated with band 3 protein and other membrane proteins (Puchulu-Campanella et al., 2013). These enzymes, as well as pyruvate kinase and lactate dehydrogenase form a multi-enzyme complex. Hemoglobin in the deoxygenated state has a high affinity for CDB3 (D'Alessandro et al., 2015; Sega et al., 2015; Kosmachevskaya et al., 2019; Zhou et al., 2019). An increase in the proportion of deoxyhemoglobin (deoxyHb) under hypoxia leads to the displacement of glycolysis enzymes from the CDB3 binding site and their transition to a soluble active state (D'Alessandro et al., 2015; Kosmachevskaya et al., 2019). It is believed that the redistribution of hemoglobin $(\mathrm{Hb})$ between soluble and membrane-bound forms switches metabolism from the pentose phosphate pathway to the glycolytic in response to changes in cell oxygen status (D'Alessandro et al., 2015; Sega et al., 2015; Andreyeva et al., 2019). On the one hand, it increases the level of intracellular ATP, and, on the other hand, reduces the glucoses flux that enter the pentose phosphate pathway, which produces NADPH, necessary for the work of antioxidant enzymes, and reduced glutathione. Because CDB3 is the center of erythrocyte membrane organization and the regulator of ionic homeostasis, even minor changes in CDB3 binding lead to changes in the morpho-biochemical properties of cells (Ugurel et al., 2020).

As oxygen-carrying cells, RBCs are repeatedly at risk of oxidative damage (Cortese-Krott \& Shiva, 2019). In fact, about 3\% of hemoglobin undergoes autooxidation during oxygen dissociation to form oxidized $\mathrm{Hb}$ and superoxide anion radical, which after dismutation forms hydrogen peroxide $\left(\mathrm{H}_{2} \mathrm{O}_{2}\right)$ (Ratanasopa et al., 2015; Rocha et al., 2015; Kuhn et al., 2017). Oxidation of hemoglobin by $\mathrm{H}_{2} \mathrm{O}_{2}$ can cause structural modifica- 
tions of the globin molecule (Lin et al., 2015; Ratanasopa et al., 2015; Rocha et al., 2019). Oxidation of cysteine residues leads to partial breakdown of its $\beta$-chain. Membrane rearrangement in response to oxidants (Boulet et al., 2018) can affect the structure of a protein (be a denaturing agent) by enhancing electrostatic interactions near its surface, namely, by the combined action of local $\mathrm{pH}$ reduction and dielectric constant (Bychkova et al., 2014). Thus, oxidized hemoglobin, especially its low-spin forms (hemichrome), have an increased ability to bind to the membrane. Additional ways of binding cytoplasmic proteins to the erythrocyte membrane, such as covalent binding through disulfide bonds and hydrophobic interactions, may occur during the interaction. It has been shown that the oxidation state of hemoglobin (from $\mathrm{Fe}(\mathrm{III})$ to $\mathrm{Fe}(\mathrm{V})$ ) correlates with the binding intensity, with approximately $50 \%$ of this binding requiring reactive sulfhydryl groups (Welbourn et al., 2017). Methemoglobin (MetHb), which is not reduced by membrane-bound methemoglobin reductases, degrades to hemichromes $(\mathrm{HemiCr})$ that accumulate in the membrane forming Heinz bodies, causing aggregation of band 3 protein and additional membrane remodeling. Increased amounts of membrane-bound $\mathrm{Hb}$ have recently been associated with many diseases of the blood system caused by antioxidant disorders and the action of various xenobiotics (Carelli-Alinovi \& Misiti, 2017; Welbourn et al., 2017; Kosmachevskaya et al., 2019; Tharaux, 2019).

Catalase (CAT), glutathione peroxidase (GPx) and peroxiredoxin (Prx2) are involved in preventing the accumulation of $\mathrm{H}_{2} \mathrm{O}_{2}$ in $\mathrm{RBC}$ by converting $\mathrm{H}_{2} \mathrm{O}_{2}$ to water and $\mathrm{O}_{2}$. CAT, GPx and $\mathrm{Prx} 2$ are essentially cytosolic enzymes; however, the association of these enzymes with the erythrocyte membrane has been reported in different in vivo and in vitro studies (Bayer et al., 2016; Melo et al., 2019; Rocha et al., 2019). The authors of these studies believe that the binding of these cytosolic enzymes to the membrane is caused by metabolic stress, possibly to protect the erythrocyte membrane and counteract the effects of oxidative stress. Catalase has been shown to retain its activity upon membrane binding (Aviram \& Shaklai, 1981), while GPx and Prx2 not (Rocha et al., 2015).

Superoxide dismutase (CuZnSOD, SOD1) is another fundamental antioxidant enzyme that is the only form of SOD in mature mammalian erythrocytes. Erythrocytes deficient in this enzyme have been shown to have a shorter lifespan due to increased levels of reactive oxygen species, lipid peroxidation products, increased hemoglobin susceptibility to oxidation, and Heinz bodies formation (Grzelak et al., 2009). It has been shown that under conditions of normoxia, membrane-bound SOD1 compounds form $0.1 \%$ of the total mass of membrane proteins. Under conditions of hypoxia, its content increases 1.5 times (Sidorenko et al., 2018).

In connection with the above, we continue to study the effect of the radical-generating system $\mathrm{Asc}-\mathrm{Cu}^{2+}$ on erythrocytes in suspension with different glucose content. We study the effect of glucose and mild oxidative environment on the accumulation dynamics of membrane-bound hemoglobin, the distribution of ligand forms in its cytoplasmic and membrane-bound fractions. We determine the activity of membrane-associated and cytoplasmic forms of the enzymes SOD1 and catalase and evaluate the levels of $\mathrm{H}_{2} \mathrm{O}_{2}$ in the extracellular environment and in erythrocytes. Analyzing the experimental data, we try to explain the interaction of cytoplasmic proteins with the membrane caused by oxidative stress and glucose.

\section{Materials and methods}

The protocol of the experimental part was corresponded to the principles of biological ethics and was agreed upon with the Local Ethics Committee of the Vasyl' Stus Donetsk National University, Faculty of Chemistry, Biology and Biotechnology (Vinnitsa, Ukraine).

Peripheral blood of healthy donors of one sex and about one age was used in the study. Erythrocytes were washed three times with centrifugation in Na-phosphate buffer ( $0.015 \mathrm{M}, \mathrm{pH} 7.4)$, containing $0.15 \mathrm{M}$ of $\mathrm{NaCl}$ (buffer solution 1). Plasma was washed out and packed erythrocytes were resuspended in the same buffer with different glucose content. The amount of glucose was added in correspondence to the quantity of packed erythrocytes in the suspension to the final concentration range 0 , $0.5,2,4,8 \mathrm{mM}$ per $10^{12}$ erythrocytes/L. The erythrocyte suspension was introduced into the oxidizing medium of the following composition: as- corbic acid (AscH) $-1 \cdot 10^{-4} \mathrm{M}, \mathrm{Cu}^{2+}-5 \cdot 10^{-6} \mathrm{M}$, Na-phosphate buffer $(0.015,0.15 \mathrm{M} \mathrm{NaCl}, \mathrm{pH} 7.4)$ with 5 hours incubation at $20^{\circ} \mathrm{C}$. The number of erythrocytes in the incubation medium was maintained at a level corresponding to $3.0-3.2 \mathrm{mg} / \mathrm{mL}$ hemoglobin content. After selected intervals, the sample was washed by centrifugation with Na-phosphate buffer ( $\mathrm{pH}$ 7.4), after which the washed erythrocytes were resuspended in the original volume of the same buffer.

For further studies (1) erythrocytes washed from the oxidizing medium in a buffer solution 1, (2) hemolysate of erythrocytes washed from the oxidizing medium, (3) erythrocytes ghosts were used.

Hemolyzate for catalase and SOD1 activity determination was obtained by adding $0.3 \mathrm{~mL}$ of $0.02 \%$ saponin solution in $0.01 \mathrm{MNa}-$ phosphate buffer ( $\mathrm{pH} 7.4$ ) to $1 \mathrm{~mL}$ of erythrocyte suspension. Hemolysis was performed in cold for 10 minutes.

As control, erythrocytes that were not exposed to radical-generating systems and were in buffer solution 1 with the appropriate amount of glucose were used. The activity of membrane-bound enzymes was determined using whole erythrocytes, the activity of the cytoplasmic fraction was determined by the difference between the activity of hemolysates and the activity recorded on the cell surface.

Superoxide dismutase activity was estimated on the basis of the inhibition of the adrenaline autooxidation in an alkaline medium (carbonate buffer) (Sirota, 1999; Grzelak et al., 2009). The oxidation product of adrenaline has an absorption in the region of $347 \mathrm{~nm}$, its formation occurs in the absence of additional generation factors and is sensitive to SOD1. The magnitude of SOD1 activity in hemolysates and whole erythrocyte cells was judged by the degree of enzyme inhibition by the rate of adrenaline autooxidation. SOD1 activity was counted on the amount of hemoglobin in the sample (mg).

Catalase activity was determined by the rate of utilization of hydrogen peroxide $\left(\mathrm{H}_{2} \mathrm{O}_{2}\right)$. The amount of $\mathrm{H}_{2} \mathrm{O}_{2}$ was determined using a Fox reagent (Wolff \& Dean, 1987). The activity of the enzyme was expressed as the $\mu \mathrm{M}$ of substrate $\left(\mathrm{H}_{2} \mathrm{O}_{2}\right)$, converted by the enzyme per min, per $\mathrm{mg}$ of hemoglobin $(\mathrm{Hb})$ in the sample.

The $\mathrm{H}_{2} \mathrm{O}_{2}$ content in the extracellular medium was determined using Fox-reagent, after cell precipitation by centrifugation. The cytosol $\mathrm{H}_{2} \mathrm{O}_{2}$ content was determined in lysate obtained by subsequent lysis of cells in $0.5 \mathrm{~mL}$ of cold water and precipitation proteins by TCA acid (Wolff, 1994; Bou et al., 2008).

The content of membrane-bound hemoglobin and its ligand forms were assessed after cells incubation for 5 hours in $\mathrm{Cu}^{2+}-$ Asc medium without and in presence of glucose at concentrations of 4 and $8 \mathrm{mMper}$ of $10^{12}$ of cells $/ \mathrm{L}$.

At certain intervals, erythrocytes were lysed by adding $5(7) \mathrm{mL}$ of $0.01 \mathrm{M} \mathrm{Na}-\mathrm{K}$-phosphate buffer $(\mathrm{pH} 7.4) \mathrm{T}=4^{\circ} \mathrm{C}$. The ghosts were precipitated by centrifugation $(10 \mathrm{~min}, 3000 \mathrm{rpm})$, the total hemoglobin content and content of ligand forms of hemoglobin in the supernatant was examined. Erythrocyte ghosts were washed with buffer 1 and dissolved in 0.5 (0.2) $\mathrm{mL}$ of $5 \%$ Triton X-100 solution (Ratanasopa et al., 2015; Rocha et al., 2019). The sample was kept for 5 min until complete clarification of the solution and then buffer 1 was added.

The absorption spectra of cytoplasmic and membrane-bound hemoglobin of erythrocytes were recorded in the wavelength range $500-700 \mathrm{~nm}$ in cuvettes with a thickness of $1 \mathrm{~mm}$. A solution containing $0.5(0.2) \mathrm{mL}$ of 5\% Triton X-100 and buffer solution 1 was used as a reference solution for spectrophotometric measurements to study of membrane-bound hemoglobin. The total content of cytoplasmic and membrane-bound fractions of hemoglobin was determined by absorption at a wavelength $223 \mathrm{~nm}$ using an extinction coefficient of $7120 \mathrm{M} / \mathrm{cm}$ (Ratanasopa et al., 2015).

To determine the content of ligand forms of hemoglobin, the absorption at 540, 560, 576 and $630 \mathrm{~nm}$ (Attia et al., 2019) was recorded. The content $(\mathrm{C})$ of ligand forms of hemoglobin (in M) was calculated using the equations given in (Benesch et al., 1973):

$$
\begin{aligned}
\mathrm{C}_{\mathrm{OxyHb}} & =\left(1.4747 \cdot \mathrm{A}_{576}-0.6820 \cdot \mathrm{A}_{560}-0.5329 \cdot \mathrm{A}_{540}\right) \cdot 10^{-4}, \\
\mathrm{C}_{\mathrm{MetHb}} & =\left(4.5852 \cdot \mathrm{A}_{540}-0.8375 \cdot \mathrm{A}_{560}-3.7919 \cdot \mathrm{A}_{576}\right) \cdot 10^{-4}, \\
\mathrm{C}_{\mathrm{deoxyHb}} & =\left(1.4749 \cdot \mathrm{A}_{560}+0.2141 \cdot \mathrm{A}_{576}-1.1042 \cdot \mathrm{A}_{540}\right) \cdot 10^{-4}, \\
\mathrm{C}_{\mathrm{HemiCr}} & =\left(\left(1.8787 \cdot \mathrm{A}_{560}-1.4061 \cdot \mathrm{A}_{576}-\mathrm{A}_{630}\right) / 8.6888\right) 10^{-4},
\end{aligned}
$$

where $\mathrm{A}_{540}, \mathrm{~A}_{560}, \mathrm{~A}_{576}$, and $\mathrm{A}_{630}$ are the absorbances measured experimentally at respective wavelengths for experimental $\mathrm{Hb}$ solutions (Attia et al., 
2015). The content of each form was expressed as a percentage of the total hemoglobin content in the cytoplasmic (membrane-bound) fraction. The total hemoglobin content in erythrocytes was determined by the hemiglobin cyanide unified method according to the standard set at a wavelength $540 \mathrm{~nm}$.

All experiments were performed in five replicates. The data were analyzed in the Statistica 8.0 (StatSoft Inc., USA) software. The data are presented in the tables as $\mathrm{x} \pm \mathrm{m}(\mathrm{x}-$ mean, $\mathrm{m}$ - error). The statistical relationship between the pairs of studied indicators was evaluated using the Spearman correlation coefficient (r). Significance of correlation coefficients $(\mathrm{P}<0.05)$ was determined by Student's t-test. To construct the distribution curves of the ligand forms of hemoglobin we used the approximation of data by the method of least squares in accordance with the equation of polynomial regression of the 6 th degree.

\section{Results}

The $\mathrm{H}_{2} \mathrm{O}_{2}$ change in erythrocytes (b) and extracellular medium during 5 hours of incubation are shown in Figure 1 with indication of the absolute values of $\mathrm{H}_{2} \mathrm{O}_{2}$ in the extracellular environment that could be used to compare its amount in the medium without cells. The data obtained indicate the ability of erythrocytes to effectively neutralize extracellular hydrogen peroxide. Glucose at the maximum studied concentration was involved in the production of $\mathrm{H}_{2} \mathrm{O}_{2}$, as evidenced by the gradual increase of the latter $\left(\mathrm{H}_{2} \mathrm{O}_{2}\right.$ content at the end of the experiment reached $\left.10.9 \pm 1.06 \mu \mathrm{M}\right)$.

The relative changes in cytoplasmic hydrogen peroxide are shown in Figure $1 \mathrm{~b}$. The baseline level of $\mathrm{H}_{2} \mathrm{O}_{2}$, its content in cells before placement in an oxidizing medium was considered. In the absence of glucose in the incubation medium, $\mathrm{H}_{2} \mathrm{O}_{2}$ gradually accumulated. Intracellular oxidative stress developed 15-20 min after the introduction of erythrocytes into the $\mathrm{Cu}^{2+}-$ AscH system (Fig. 1b) and could be explained by the high activity of membrane-associated SOD1 $(r=0.86)$ and not the flow of hydrogen peroxide into the cell (no correlation). Addition of glucose to the extracellular medium at the concentration 0.5 and $2.0 \mathrm{~mm}$ reduced the amount of $\mathrm{H}_{2} \mathrm{O}_{2}$ in both the extracellular environment and the cytosol of cells. The presence of glucose at concentration 4 and $8 \mathrm{~mm}$ contributed to an increase in hydrogen peroxide in the extracellular environment, but in these cases $\mathrm{H}_{2} \mathrm{O}_{2}$ did not accumulate in the cells themselves, and even at some intervals its level in the cytosol fell below baseline.

The changes of membrane-bound SOD1 in the absolute activity units are shown in Figure 2. In glucose-free medium, during the first three hours of the experiment $(0-180 \mathrm{~min})$ the activity of membrane-bound SOD1 increased by $2.3 \pm 0.4$. The activity of SOD1 in the cytoplasm (data not shown) decreased by $9.7 \pm 1.28$. After $210 \mathrm{~min}$ of incubation, the activity of membrane-bound SOD1 decreased rapidly, and at the end of the experiment had lost more than $70 \%$ of its activity. The activity of SOD1 in the cytoplasm increased, but was reduced by 4 times from baseline.

Addition of glucose (up to $2 \mathrm{~mm}$ ) resulted in a smaller increase in the activity of membrane-bound SOD1 relative to the control level, but the activity of the enzyme remained stable throughout the experiment. In the cytoplasm the SOD1 activity remained low. In experiments with a glucose concentration of 4 and $8 \mathrm{~mm}$, the nature of the change in SOD1 activity was different: SOD1 activity gradually decreased by half during 90-150 min from the beginning of the experiment, with subsequent increase, but still remained below the control. However, we were not able to detect SOD1 activity in the cytoplasm.

The change of membrane-bound and cytoplasmic catalase activity in the erythrocytes depending on the level of glucose in the incubation medium is shown in Figure 3. At glucose concentrations of 0-2 mM, the activity of membrane-bound catalase varied in two phases: for 90 $120 \mathrm{~min}$ it decreased by an average of $20 \%$, then increased to the control level. The rise in glucose concentration in the incubation medium led to an increase in the activity of the membrane-bound enzyme, especially at the end of the experiment. At $4 \mathrm{mM}$ glucose, the activity of membrane-bound catalase was $1.41 \pm 0.11$ times higher and at $8 \mathrm{mM} 1.23 \pm 0.06$ times higher than the baseline (Fig. 3a). The activity of cytoplasmic catalase under conditions of glucose depletion dropped significantly: after $90 \mathrm{~min}$ from the beginning of the experiment by $60.0 \pm 14.7 \%$, at the end of the experiment by $80.6 \pm 8.6 \%$ (Fig. $3 b$ ).
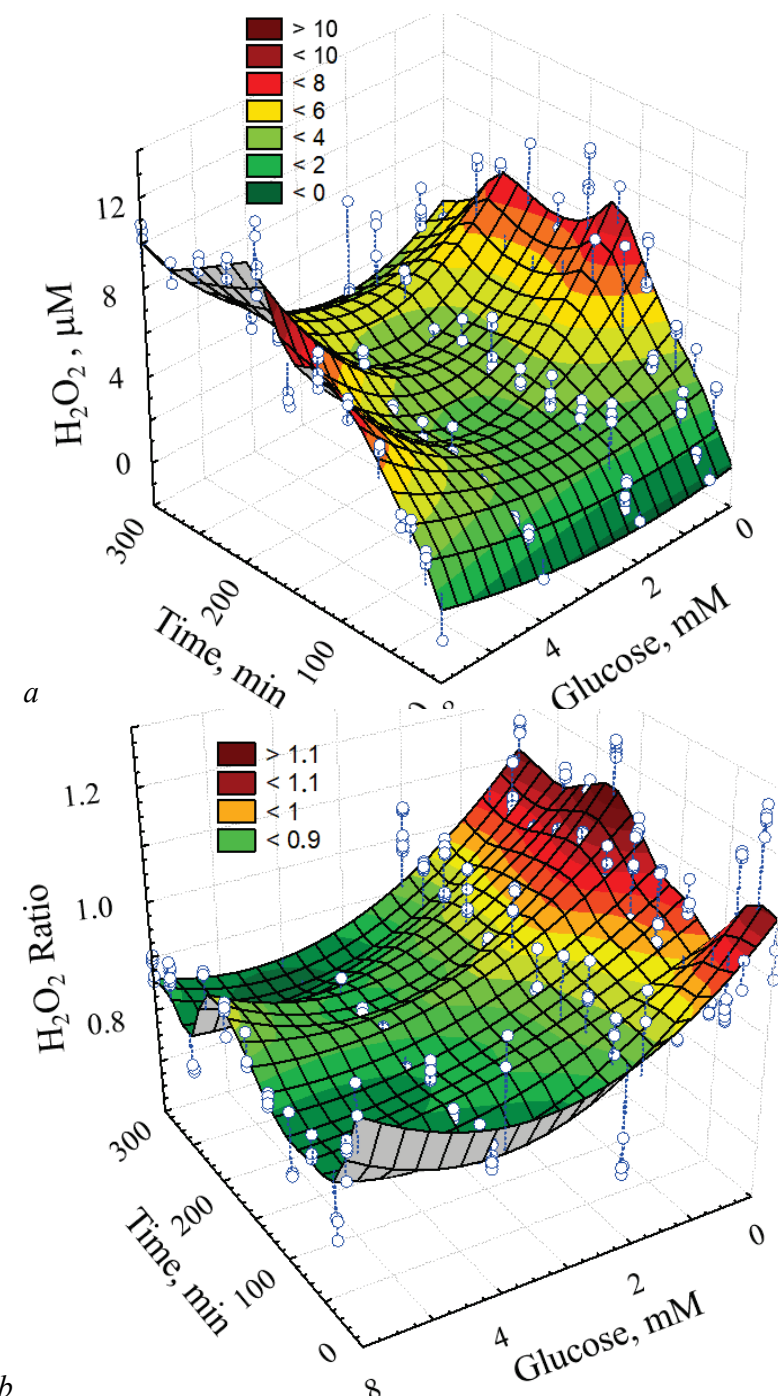

8

Fig. 1. The change in the content of hydrogen peroxide in the extracellular medium $(a)$ and the cytosol of the cell $(b)$ depending on the incubation time of the cells and the glucose load $(n=360, n=5)$

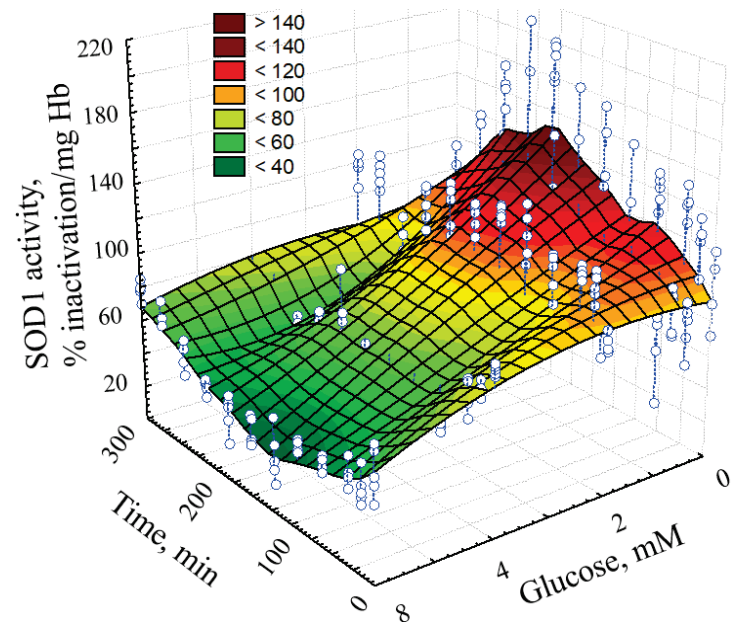

Fig. 2. The change in SOD1 activity of erythrocyte surface activity depending on incubation time of cells and glucose load $(n=180, n=5)$

The introduction of glucose into the incubation medium in the amount of 2 and $4 \mathrm{mM}$ contributed to a significant increase in the activity of cytoplasmic catalase for $150 \mathrm{~min}$ of the experiment, after that the catalase activity decreased to the level of control and 30\% below control, respectively. At $8 \mathrm{mM}$ glucose concentration an increase in activity was observed at the beginning of the experiment with a gradual decrease in activity by 
$69.5 \pm 1.4 \%$. The correlation coefficient between the activities of membrane-bound and cytoplasmic catalase was -0.77 in experiments with high glucose concentration ( 4 and $8 \mathrm{mM})$.

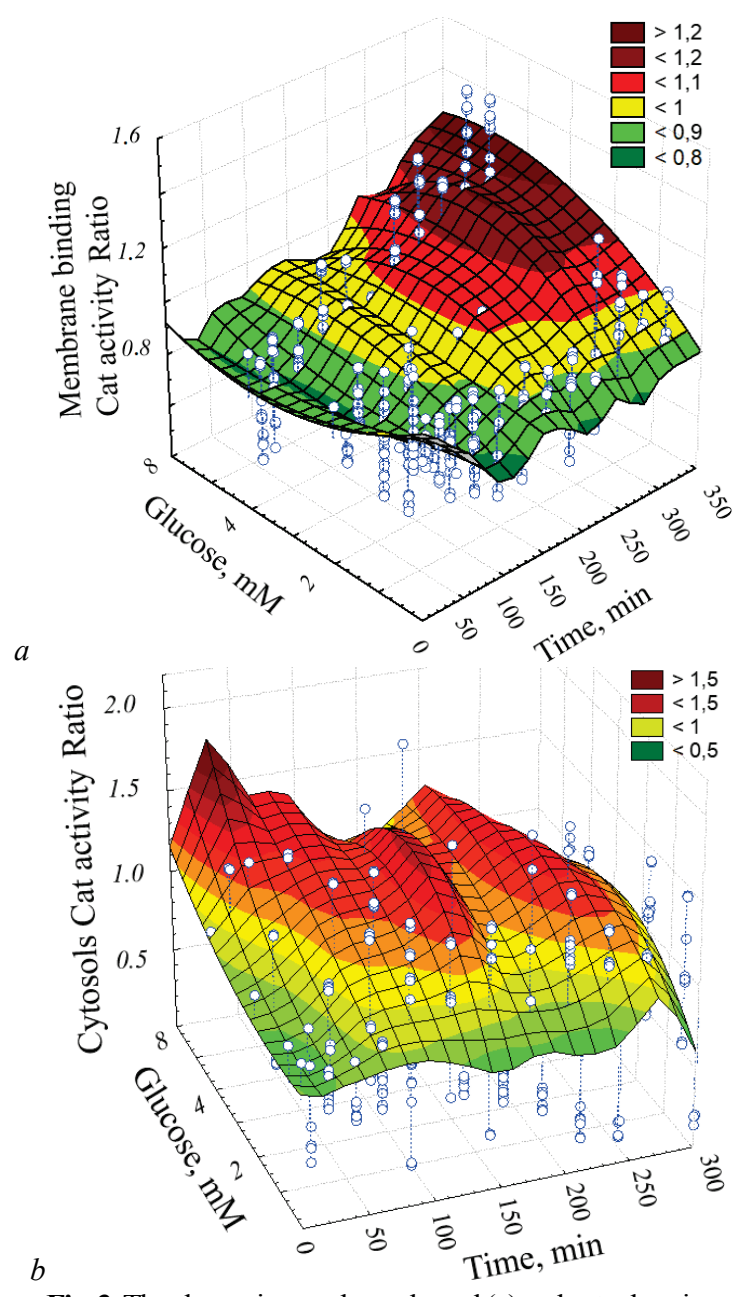

Fig. 3. The change in membrane-bound $(a)$ and cytoplasmic catalase $(b)$ activity depending on the incubation time of the cells and the glucose load $(n=360, n=5)$

During incubation the level of membrane-bound hemoglobin reached a certain equilibrium level. The initial level of membrane-bound hemoglobin varied at control points from 1.5 to $10.0 \%$ and depended on the conditions of cell secretion and the presence of glucose. After one hour of incubation, equilibrium levels of membrane-bound hemoglobin were established in the cells and maintained until the end of the experiment. In cells incubated without glucose the level of membrane-bound hemoglobin was $4.43 \pm 0.56 \%$ of total hemoglobin. In cells incubated in medium with $4 \mathrm{mM}$ glucose it was $2.25 \pm 0.31 \%$, and in $8 \mathrm{mM}$ glucose $-3.36 \pm$ $0.78 \%$, but in latter case, during the last hour of incubation, the content of membrane-bound hemoglobin decreased almost twice and was $1.88 \pm 0.08 \%$.

The changes in ligand forms of cytoplasmic $(a)$ and membranebound $(b)$ hemoglobin in erythrocytes incubated in glucose-free medium are shown in Figure 4. The content of $\mathrm{OxyHb}$ in the cytoplasmic fraction during $120 \mathrm{~min}$ of incubation decreased to $64.8 \pm 0.78 \%$, the amount of methemoglobin increased to $34.6 \pm 1.8 \%$ (Fig. $4 a$ ). These parameters correlated with the content of hydrogen peroxide in the cells. At the end of incubation, the level of MetHb decreased slightly, and the content of oxyhemoglobin remained at $71 \pm 1.1 \%$ (Fig. 4a). The correlation coefficient between $\mathrm{OxyHb}$ and $\mathrm{MetHb}$ is -0.87 and between $\mathrm{DeoxyHb}$ and $\mathrm{MetHb}$ was -0.7 . In the membrane-bound hemoglobin fraction, the $\mathrm{OxyHb}$ content ranged $60-75 \%$, the DeoxyHb content 3-10\%, and the MetHb content ranged $20-38 \%$. A significant correlation coefficient $(-0.59)$ was found only between DeoxyHb and MetHb. The hemichrome content in the cell did not exceed $2 \%$.
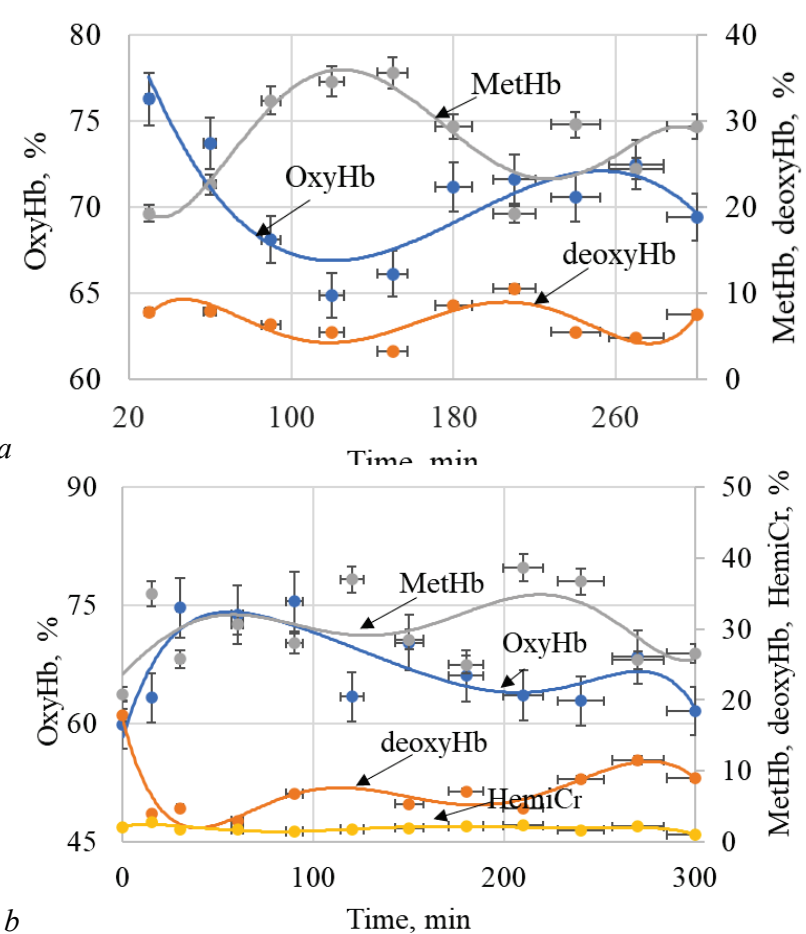

Fig. 4. The distribution of ligand forms in the composition of cytoplasmic $(a)$ and membrane-bound $(b)$ fractions of erythrocytes hemoglobin that were incubated in $\mathrm{AscH}-\mathrm{Cu}^{2+}$ medium without glucose: each point represents the $\mathrm{x} \pm \mathrm{m}$ for $\mathrm{n}=5$

The changes in the ligand forms of cytoplasmic $(a)$ and membranebound $(b)$ hemoglobin in erythrocytes incubated in a $4 \mathrm{~mm}$ glucose medium are shown in Figure 5. The average level of oxyhemoglobin in the cytoplasm was $78.3 \pm 2.4 \%$, deoxyhemoglobin $7.0 \pm 2.2 \%$, the level of methemoglobin was lower and ranged from $11.3 \pm 0.6 \%$ to $22.6 \pm 1.0 \%$. The correlation between $\mathrm{OxyHb}$ and $\mathrm{MetHb}$ in the cytoplasmic fraction was -0.82 . In addition, membrane-bound hemoglobin significantly decreased oxyhemoglobin levels due to an increase in deoxyform. After $100 \mathrm{~min}$ of incubation, the level of $\mathrm{OxyHb}$ in the membrane was $37.4 \pm$ $0.8 \%$, deoxyHb $-23.5 \pm 2.3 \%$. The maximum level of methemoglobin $30.8 \pm 2.8 \%$ was recorded only at the beginning of the experiment, and later its amount decreased almost twofold. We recorded a slightly elevated level of hemichrome in the membrane-bound form, but its content remained approximately constant (4-5\%) throughout the experiment. No significant correlations were found between the ligand forms in membranebound hemoglobin, but a correlation was found between the activity of membrane-bound SOD1 and $\mathrm{OxyHb}(\mathrm{r}=0.56)$ and deoxyHb $(\mathrm{r}=0.76)$.

In the cytosol of erythrocytes incubated in a medium with $8 \mathrm{mM}$ glucose (Fig. 6a) the content of $\mathrm{OxyHb}$ was $76.8 \pm 3.6 \%$, deoxyHb $-8.8 \pm$ $1.8 \%$. MetHb was maintained at $22.1 \pm 2.1 \%$ for $120 \mathrm{~min}$, and then began to decline. At the end of the experiment, the MetHb content increased to $25.3 \pm 0.4 \%$ of the total amount of cytoplasmic hemoglobin. The distribution of ligand forms in membrane-bound hemoglobin (Fig. 6b) is also very similar, but the decrease in oxyhemoglobin content began only after 120 min of cell incubation. The content of ligand forms in the composition of membrane-bound hemoglobin correlates with the activity of membrane-bound SOD1.

\section{Discussion}

Oxidative stress plays an important role in pathogenic conditions, leading to direct cell damage and affecting dozens of metabolic pathways. Cell membranes in general and the erythrocyte membrane in particular are very sensitive to oxidative damage. Various active oxygen species, such as hydroxyl radicals, singlet oxygen, superoxide and $\mathrm{H}_{2} \mathrm{O}_{2}$, initiate lipid peroxidation, leading to loss of membrane integrity. Glutathione peroxidase, superoxide dismutase and catalase are involved in erythrocytes' protective mechanisms against the deleterious effects of oxidizing products. Location 
of these enzymes in the proximity of the membrane would significantly increase their efficiency in the scavenging of reactive oxygen species.
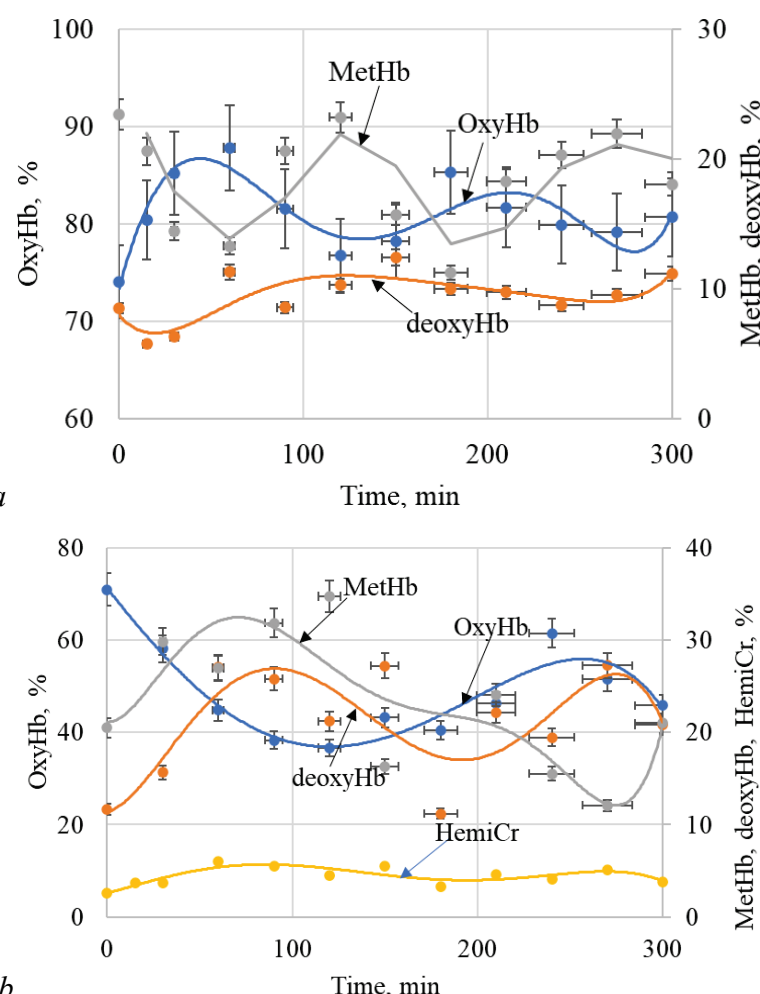

Fig. 5. The distribution of ligand forms in the composition of cytoplasmic (a) and membrane-bound (b) fractions of erythrocytes' hemoglobin that were incubated in $\mathrm{AscH}-\mathrm{Cu}^{2+}$ medium with $4 \mathrm{mM}$ glucose: each point represents the $\mathrm{x} \pm \mathrm{m}$ for $\mathrm{n}=5$

It is known that erythrocytes rearrange the membrane under the influence of various external factors (Carelli-Alinovi \& Misiti, 2017; Boulet et al., 2018), resulting in a violation of the asymmetry of the lipids' location and the charge of the membrane surface. In this case, with a high degree of probability the protein native structure could be transformed under the action of certain internal factors into a state similar to denatured (Bychkova et al., 2014; Cheng et al., 2016). Along with natural denaturing factors, such as low $\mathrm{pH}$, thermal and salt stresses, a negatively charged membrane surface can serve as a moderate denaturing agent in the cell, due to increased electrostatic interactions at the interface between the aqueous and nonpolar phases. As a result, the membrane goes into a state other than the native, which allows the cell to function in a different physiological mode (Dotsenko et al., 2012), as this changes the work of ion transport systems, the inclusion of secondary messengers (especially calcium-mediated regulatory mechanism) that are aimed at restructuring functional state of the cell as a whole.

The obtained data suggest that the oxidative load creates the conditions for the cytoplasmic enzymes binding to the erythrocyte membrane. It is known that catalase can bind to the erythrocyte membrane (Aviram \& Shaklai, 1981; Rocha et al., 2015; Melo et al., 2019; Rocha et al., 2019). Binding occurs through electrostatic interactions between the negatively charged membrane and the enzyme (Aviram \& Shaklai, 1981), but ionic binding to the membrane involving calcium and sulfhydryl groups (Allen et al., 1977) may also occur. The outer surface of erythrocytes, bearing high negative charge as well, does not bind catalase (Aviram \& Shaklai, 1981). In respect to that, catalase resembles other components of the cytosol, such as hemoglobin and a number of glycolytic enzymes which are specifically associated with the inner side of the membrane. Moreover, the fact that catalase binding is not affected by the removal of spectrum and actin from the membrane indicates that the cytoskeletal composition does not prevent occupation of a major part of the membrane region by other proteins (Aviram \& Shaklai, 1981). It is believed that the enhanced association of CAT with the membrane is a consequence of metabolic stress caused by destabilization of the membrane structure due to its altered composition and is exacerbated by hematological diseases associated with oxidative stress, such as hereditary spherocytosis (Allen et al., 1977; Rocha et al., 2019), beta-thalassemia, erythrocyte enzymopathy, blood storage (Rocha et al., 2015; Melo et al., 2019; Rocha et al., 2019).
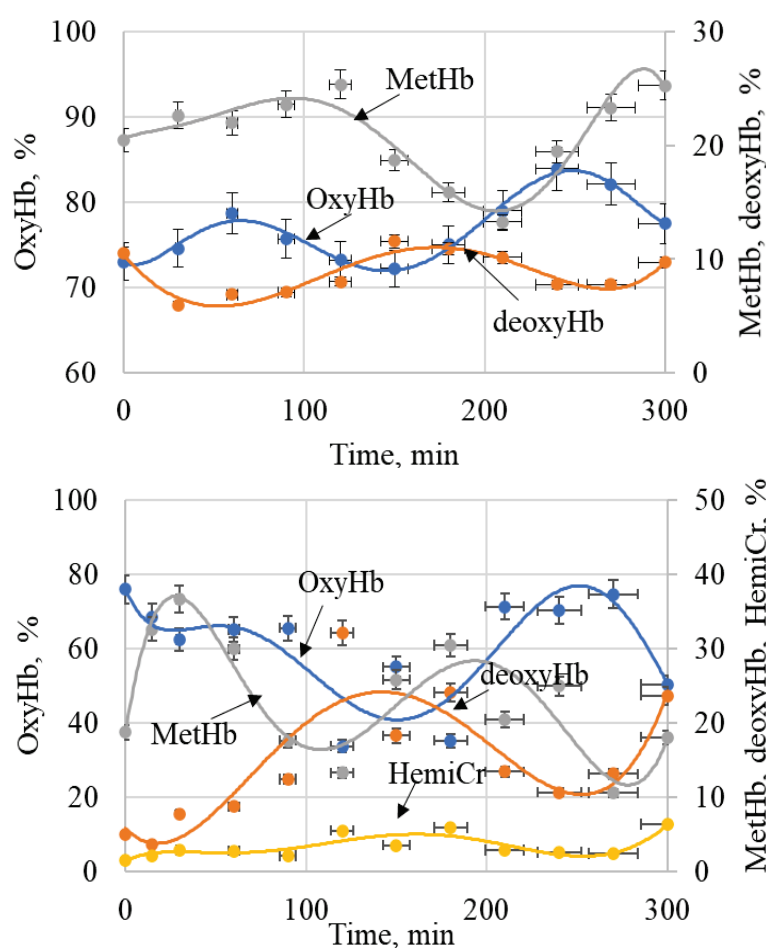

Fig. 6. The distribution of ligand forms in the composition of cytoplasmic (a) and membrane-bound $(b)$ fractions of erythrocytes hemoglobin that were incubated in $\mathrm{AscH}-\mathrm{Cu}^{2+}$ medium with $8 \mathrm{mM}$ glucose: each point represents the $\mathrm{x} \pm \mathrm{m}$ for $\mathrm{n}=5$

Under conditions of glucose depletion and, as a consequence, depletion of ATP and NADPH, erythrocytes are forced to rearrange metabolic processes for survival. We show that the activities of membrane-bound catalase and SOD1 in this case correlate with the amount of external hydrogen peroxide (correlation coefficients -0.66 and 0.86 , respectively), that is the transition of enzymes to the bound state is initiated by oxidative stress and $\mathrm{H}_{2} \mathrm{O}_{2}$ production externally. At the beginning of the experiment, the catalase activity of intact cells and hemolysate coincided. During the $90 \mathrm{~min}$ incubation, we recorded a direct correlation $(0.78)$ between the bound and cytoplasmic forms of catalase (the activities of both forms are reduced) and the inverse $(-0.68)$ by the end of the experiment. The fall in cytoplasmic enzyme activity was $80.6 \pm 8.6 \%$, while its increase on the surface was only $21.3 \pm 6.0 \%$. Catalase converts to a membrane-bound form with activity loss of unknown mechanisms. The deeper location of the heme may be advantageous during its interaction with the membrane when the protein is exposed to phospholipids. The result of this interaction may be the location of the prosthetic group between the lipid and protein phases (Aviram \& Shaklai, 1981), which leads to a loss of enzymatic activity. But we do not rule out the possibility of binding catalase in the oligomeric state. Earlier we showed (Taradina \& Dotsenko, 2011) that the action of very weak factors leads to denaturation changes in the active center of native catalase, resulting in the formation of various oligomeric intermediates, among which there are partially denatured and dissociated forms with reduced activity, compared with the tetrameric form. Our hypothesis is evidenced (Allen et al., 1977) by the fact of the existence of monomeric catalase without loss of subunit structure, completely inactive form in erythrocytes of patients with hereditary spherocytosis.

In terms of energy, erythrocytes are dependent on the glucose consumption, which is metabolized in the reactions of glycolysis and pentosephosphate shunt, providing the cell with ATP and reducing equivalents. In the current study we showed that the presence of glucose in the incubation medium affects the behaviour of antioxidant enzymes and their binding to the membrane. At low glucose concentrations (up to $4 \mathrm{mM}$ ), catalase passes into the membrane with virtually no loss of activity. Thus, the 
activity of cytoplasmic catalase after 5 hours of incubation in solutions with a glucose content of $4 \mathrm{mM}$ is reduced by $30.0 \pm 1.3 \%$, while the activity of membrane-bound catalase increases by $26.0 \pm 1.1 \%$ (correlation coefficient between the two forms of the enzyme $-0,77$ ). Addition of glucose to the oxidizing environment attracts glucose to the formation of hydrogen peroxide. The $\mathrm{H}_{2} \mathrm{O}_{2}$ content increases in the extracellular environment, especially at the end of incubation. The activity of cytoplasmic catalase of erythrocytes at the end of the experiment in solutions with $8 \mathrm{mM}$ glucose content decreases by $59.5 \pm 1.4 \%$ and the activity of membrane-bound catalase increases by $5.8 \pm 1.3 \%$. Thus, we have shown that the more $\mathrm{H}_{2} \mathrm{O}_{2}$ accumulates externally, the more inactivated bound catalase in the membrane is observed (inactivation of $\mathrm{H}_{2} \mathrm{O}_{2}$ catalase is a known fact). It is believed that extracellular $\mathrm{H}_{2} \mathrm{O}_{2}$ freely enters the cytoplasm of the cell. Earlier (Dotsenko et al., 2010), we investigated in detail the ability of a system, containing $\mathrm{Cu}^{2+}$ ions and ascorbic acid (AscH), to increase the production of hydrogen peroxide. We showed that in the $\mathrm{Cu}^{2+}-\mathrm{AscH}$ system the content of $\mathrm{H}_{2} \mathrm{O}_{2}$ increases over time and reaches $43.6 \pm 0.87 \mu \mathrm{M}$ five hours from the start of the reaction. Our data suggest that in the presence of erythrocytes, the maximum concentration of $\mathrm{H}_{2} \mathrm{O}_{2}$ reaches $10.9 \pm 1.06 \mu \mathrm{M}$ in the medium only in the presence of glucose in the amount of $8 \mathrm{mM}$. Clearly, membrane-bound catalase is fully capable of inactivating extracellular $\mathrm{H}_{2} \mathrm{O}_{2}$, and membrane-bound glutathione peroxidase (GPx) and peroxiredoxin (Prx2)are involved in these processes (Rocha et al., 2015; Bayer et al., 2016; Melo et al., 2019; Rocha et al., 2019). It has been shown (Aviram \& Shaklai, 1981) that the cell permeability barrier for $\mathrm{H}_{2} \mathrm{O}_{2}$ is responsible for the rate of decomposition of hydrogen peroxide. The dense packing of catalase molecules under saturation conditions promotes the efficient entry of $\mathrm{H}_{2} \mathrm{O}_{2}$ into the active site, where it is consumed at a rate of $3.5 \pm 1.7 \mathrm{M}^{-1} \mathrm{c}^{-1}$ (Bonaventura et al., 1972). According to our results, no correlations have been established between cytoplasmic and extracellular $\mathrm{H}_{2} \mathrm{O}_{2}$ content, which indicates the formation of intracellular $\mathrm{H}_{2} \mathrm{O}_{2}$ due to cellular metabolic processes.

Under conditions of glucose depletion, there is an inverse correlation between cytoplasmic and membrane-associated forms of SOD1 $(-0.66)$. In contrast to catalase, the activity of membrane-bound SOD1 during the 180 min experiment increased significantly, which is unexpected for this enzyme, which is very sensitive to oxidative damage. The recorded changes in the activity of SOD1 on the surface and in the cytoplasm suggest that the binding of the enzyme occurs in a partially denatured state with loss of activity. The increase in the recorded activity of SOD1 may be explained by an increase in the number of membrane-associated forms of protein (Sidorenko et al., 2018). SOD1 has a stable intra-subunit disulfide bond (Cys58-Cys147), which is a rare structural motif in proteins involved in redox transformations. The disulfide bond of Cys58-Cys147 is maintained even if Cys147 is oxidized, and this allows SOD1 to stay in a partially active state for some time (Tiwari et al., 2019). According to these authors, the oxidative modification of SOD1, including the oxidation of a key disulfide bond, can disrupt the structural and functional properties of this enzyme, facilitating the transition of the protein to the denatured state, and this can promote binding to the membrane. After 180 minutes of the experiment, we recorded a sharp decrease in the activity of membrane-bound SOD1, which oxidizes and denatures in the membrane. The data obtained do not support the inverse mechanism of enzyme binding. It is known that SOD1 enzymopathy, associated with the formation of an unstable enzyme, is considered one of the causes of amyotrophic lateral sclerosis, as the oxidation of SOD1 can form amyloid structures (Tiwari et al., 2019).

The dependences of the change in the activity of SOD1 under the presence of glucose in the incubation medium are radically different. We recorded a gradual decrease in the activity of membrane-bound SOD1 when glucose was introduced into the incubation medium. At glucose concentrations of 4 and $8 \mathrm{mM}$, all SOD1 was in membrane-bound state, its activity decreased for 150-180 min from the beginning of the experiment, and only then grew. This indicates additional variants of SOD1 binding with the membrane, rather than activation by glucose alone. It is known that SOD1 transmits signals from oxygen and glucose to repress respiration (Reddi \& Culotta, 2013). The mechanism involves SOD1-mediated stabilization of two homologs of 1-gamma (CK1 $\gamma)$ casein kinase, Ycklp and Yck2p, required to inhibit oxygen binding. SOD1 binds the C-terminal degron to Yck1p/Yck2p, and promotes kinase stability by catalyzing the conversion of superoxide to peroxide (Reddi \& Culotta, 2013). $\mathrm{H}_{2} \mathrm{O}_{2}$ plays a role in signaling by activating intracellular tyrosine kinases. In this case, the specific oxidation of sulfhydryl groups of cysteine causes conformational changes that lead to kinase activation (Wang et al., 2018). The effect of SOD1 on the stability of $\mathrm{CK} 1 \gamma$ is observed in mammal and human cell lines. In a single circuit, oxygen, glucose, and reactive oxygen can suppress respiration through SOD1/CK1 $\gamma$ signaling. This mechanism is not described for erythrocytes, but we believe that the binding of SOD1 to casein kinase causes a decrease in enzyme activity. This is indicated primarily by the presence of serine/threonine casein kinases of type I and II in erythrocytes. Casein kinase I phosphorylates CDB3, regulates the structural properties of the erythrocyte membrane (Wang et al., 1997). Casein kinase II is a common regulator of intracellular signaling and metabolism, phosphorylating a wide range of proteins. In erythrocytes, casein kinase II has a modulating effect on transmembrane electron transport (Iakovenko et al., 2012). Secondly, we show a correlation between the activity of SOD1 with the content of intracellular hydrogen peroxide (0.52) and with ligand forms of membrane-bound hemoglobin - $\mathrm{OxyHb}$ $(0.53)$, deoxyHb $(-0.75)$, HemiCr $(-0.77)$. The content of deoxyHb in the composition of membrane-bound hemoglobin increases significantly (Fig. 5b). It is known that an increase in the proportion of deoxyHb under hypoxia leads to the displacement of glycolysis enzymes from the binding site to CDB3 and their transition to a soluble active state (D'Alessandro et al., 2015; Chu et al., 2016; Andreyeva et al., 2019; Kosmachevskaya et al., 2019), the metabolic flow is directed to the glycolytic pathway, which allows the production of ATP. During this time, the pentose phosphate pathway of glucose metabolism is inhibited and glycolysis is activeted, which reduces the ability of erythrocytes to synthesize NADPH and reduce glutathione, which in turn are required for the reduction of dehydroascorbate to ascorbate as one of the electron transport donors (Tu et al., 2017). In this case, the electron transport chain uses glycolytic NADH as the main electron donor.

The transition from $\mathrm{Hb}$ from soluble to membrane-bound state can be both physiological and destructive. In the case of reversible interaction with membranes, the spatial redistribution of $\mathrm{Hb}$ enables the level of cellular metabolism to change, which is especially important for erythrocytes, which lack the apparatus of biosynthesis (Rifkind \& Nagababu, 2013; Kosmachevskaya et al., 2019). The formation of membrane-bound hemoglobin may be one of the mechanisms for the formation of a rapid adaptive response to changing conditions. As a hemoprotein, hemoglobin itself is able to generate a hydroxyl radical in the presence of $\mathrm{H}_{2} \mathrm{O}_{2}$. The consequence of the involvement of hemoglobin in redox reactions is the modification of amino acid residues of different nature (Lin et al., 2019). Covalent modification of proteins affects various biological processes, including activation or inactivation of protein functions. It is believed that modified methemoglobin, which is unable to be reduced by methemoglobin reductases, may bind to the membrane to form hemichrome. The level of hemichrome in cells incubated under conditions of glucose depletion is $1.92 \pm 0.42 \%$. In the presence of glucose we record a slightly higher content of hemichrome in the composition of membrane-bound hemoglobin (up to $5 \%$ ). The content of all three ligand forms of hemoglobin $(\mathrm{OxyHb}$, deoxyHb, MetHb) correlate with each other within one fraction, and there are no links between fractions. This suggests that the transformations involved in membrane-bound hemoglobin occur in the membrane itself (Welbourn et al., 2017). Bound hemoglobin during the study was fully functional, able to react with oxygen and form a functional complex. Bound hemoglobin is also oxidatively active, the oxyform can be autoxidized to methemoglobin, which in turn can be reduced by both membranebound reductases and cell reductants. The fact that deoxyform was not accumulating indicates the possibility of its oxygenation. Methemoglobin is functionally active and a decrease in its content is not associated with an increase in hemichrome content in cells.

\section{Conclusion}

Binding of catalase and SOD1 to the erythrocyte membrane is initiated by oxidative stress and is a physiological function aimed at complete inactivation of extracellular and $\mathrm{H}_{2} \mathrm{O}_{2}$ and protection against their entry 
into the cell. Binding of these enzymes to the membrane is accompanied by their partial or complete inactivation.

Under conditions of hypoxia, SOD1 is involved in the transmission of signals from oxygen and glucose to regulate intracellular metabolic processes and ATP production. In this case, the binding of SOD1 is regulatory in nature and is a tool for adjusting the properties of the membrane and carbohydrate metabolism under oxidative stress.

With mild oxidation, the amount of hemoglobin bound to the membrane does not change, indicating the presence of certain binding sites for hemoglobin with membrane proteins. The study of the distribution of ligand forms in membrane-bound hemoglobin can be an informative tool for analyzing the state of cells.

\section{References}

Allen, D. W., Cadman, S., McCann, S. R., \& Finkel, B. (1977). Increased membrane binding of erythrocyte catalase in hereditary spherocytosis and in metabolically stressed normal cells. Blood, 49(1), 113-123.

Andreyeva, A. Y., Soldatov, A. A., Krivchenko, A. I., Mindukshev, I. V., \& Gambaryan, S. (2019). Hemoglobin deoxygenation and methemoglobinemia prevent regulatory volume decrease in crucian carp (Carassius carassius) red blood cells. Fish Physiology and Biochemistry, 45, 1933-1940.

Attia, A. M. M., Aboulthana, W. M., Hassan, G. M., \& Aboelezz, E. (2020). Assessment of absorbed dose of gamma rays using the simultaneous determination of inactive hemoglobin derivatives as a biological dosimeter. Radiation and Environmental Biophysics, 59(1), 131-144.

Attia, A. M. M., Ibrahim, F. A. A., Abd El-Latif, N. A., Aziz, S. W., Moussa, S. A. A. (2015). Biophysical study on conformational stability against autoxidation of oxyhemoglobin and erythrocytes oxidative status in humans and rats. Wulfenia Journal, 22(12), 264-281.

Aviram, I., \& Shaklai, N. (1981). The association of human erythrocyte catalase with the cell membrane. Archives of Biochemistry and Biophysics, 212(2), 329-337.

Bayer, S. B., Low, F. M., Hampton, M. B., \& Winterbourn, C. C. (2016). Interactions between peroxiredoxin 2 , hemichrome and the erythrocyte membrane. Free Radical Research, 50(12), 1329-1339.

Benesch, R. E., Benesch, R., \& Yung, S. (1973). Equations for the spectrophotometric analysis of hemoglobin mixtures. Analytical Biochemistry, 55(1), 245-248.

Bonaventura, J., Schroeder, W. A., \& Fang, S. (1972). Human erythrocyte catalase: An improved method of isolation and a reevaluation of reported properties. Archives of Biochemistry and Biophysics, 150, 606-617.

Bou, R., Codony, R., Tres, A., Decker, E. A., \& Guardiola, F. (2008). Determination of hydroperoxides in foods and biological samples by the ferrous oxidationxylenol orange method: A review of the factors that influence the method's performance. Analytical Biochemistry, 377(1), 1-15.

Boulet, C., Doerig, C. D., \& Carvalho, T. G. (2018). Manipulating eryptosis of human red blood cells: A novel antimalarial strategy? Frontiers in Cellular and Infection Microbiology, 8, 419.

Bychkova, V. E., Basova, L. V., \& Balobanov, V. A. (2014). How membrane surface affects protein structure. Biochemistry (Moscow), 79(13), 1483-1514.

Carelli-Alinovi, C., \& Misiti, F. (2017). Erythrocytes as potential link between diabetes and Alzheimer's disease. Frontiers in Aging Neuroscience, 9, 276.

Cheng, S. Y., Chou, G., Buie, C., Vaughn, M. W., Compton, C., \& Cheng, K. H. (2016). Maximally asymmetric transbilayer distribution of anionic lipids alters the structure and interaction with lipids of an amyloidogenic protein dimer bound to the membrane surface. Chemistry and Physics of Lipids, 196, 33-51.

Chu, H., McKenna, M. M., Krump, N. A., Zheng, S., Mendelsohn, L., Thein, S. L., Garrett, L. J., Bodine, D. M., \& Low, P. S. (2016). Reversible binding of hemoglobin to band 3 constitutes the molecular switch that mediates $\mathrm{O}_{2}$ regulation of erythrocyte properties. Blood, 128(23), 2708-2716.

Cortese-Krott, M. M., \& Shiva, S. (2019). The redox physiology of red blood cells and platelets: Implications for their interactions and potential use as systemic biomarkers. Current Opinion in Physiology, 9, 56-66.

D’Alessandro, A., Kriebardis, A. G., Rinalducci, S., Antonelou, M. H., Hansen, K. C., Papassideri, I. S., \& Zolla, L. (2015). An update on red blood cell storage lesions, as gleaned through biochemistry and omics technologies. Transfusion, 55(1), 205-219

Dotsenko, O. I., Dragushenko, O. O., \& Dotsenko, V. A. (2010). Doslidzhennia prooksydantnoi ta tsytotoksychnoi dii system $\mathrm{Cu}^{2+}-\mathrm{AscH}, \mathrm{Cu}^{2+}-\mathrm{AscH}-\mathrm{o}$-phenanthroline [The investigation of the action of prooxidant and cytotoxic systems $\mathrm{Cu}^{2+}-\mathrm{AscH}, \mathrm{Cu}^{2+}-\mathrm{AscH}-\mathrm{o}-\mathrm{phenanthroline].} \mathrm{Dosiahnennia} \mathrm{Biolohii} \mathrm{ta} \mathrm{Medy-}$ tsyny, 15, 1-7 (in Ukrainian)

Dotsenko, O. I., Troshchynskaya, Y. A., \& Konyukhova, N. R. (2012). Izuchenie processov obrazovanija membranosvjazannogo gemoglobina $\mathrm{v}$ eritrocitah pod dejstviem nizkochastotnoj vibracii [Studying of processes of formation of membrane-bound hemoglobin in erythrocytes under the influence of low- frequency vibration]. Problems of Ecology and Nature Protection of Techogen Region, 12, 274-280 (in Russian).

Grzelak, A., Kruszewski, M., Macierzyńska, E., Piotrowski, Ł., Pułaski, Ł., Rychlik, B., \& Bartosz, G. (2009). The effects of superoxide dismutase knockout on the oxidative stress parameters and survival of mouse erythrocytes. Cellular and Molecular Biology Letters, 14(1), 23-34.

Iakovenko, I. N., Zhimov, V. V., Kozachenko, A. P., Shablykin, O. V., \& Brovarets, V. S. (2012). Uchast' proteinkinazy SK2 v reguljaciji aktyvnosti redoks-systemy plazmatychnyh membran erytrocytiv ljudyny: Vidnosnyj vnesok $\mathrm{Ca}^{2+}$ zalezhnyh ta $\mathrm{Ca}^{2+}$-nezalezhnyh mehanizmiv jiji aktyvaciji [Participation of proteinkinase $\mathrm{CK} 2$ in regulation of human erythrocytes plasma membrane redox system activity: Relative contribution of $\mathrm{Ca}^{2+}$-dependent and $\mathrm{Ca}^{2+}$-independent mechanisms of its activation]. The Ukrainian Biochemical Journal, 84(5), 5560 (in Ukrainian)

Kosmachevskaya, O. V., Nasybullina, E. I., Topunov, A. F., \& Blindar, V. N. (2019). Binding of erythrocyte hemoglobin to the membrane to realize signalregulatory function (review). Applied Biochemistry and Microbiology, 55 (2), $83-98$.

Kuhn, V., Diederich, L., Keller, T. C. S. IV, Kramer, C. M., Lückstädt, W., Panknin, C., Suvorava, T., Isakson, B. E., Kelm, M., \& Cortese-Krott, M. M. (2017). Red blood cell function and dysfunction: Redox regulation, nitric oxide metabolism anemia. Antioxidants and Redox Signaling, 26(13), 718-742.

Lin, Y.-S., Wu, C.-W., Lin, T.-S., Chen, N.-Y., Wu, D.-C., \& Chen, H.-J. C. (2020). Analysis of oxidative and advanced oxidative modifications in hemoglobin of oral cancer patients by mass spectrometry. Analytical Chemistry, 92(1), 724-731.

Melo, D., Rocha, S., Coimbra, S., \& Santos Silva, A. (2019). Interplay between erythrocyte peroxidases and membrane. In: Tombak, A. (Ed.). Erythrocyte. IntechOpen, London. Pp. 486

Puchulu-Campanella, E., Chu, H., Anstee, D. J., Galan, J. A., Tao, W. A., \& Low, P. S. (2013). Identification of the components of a glycolytic enzyme metabolon on the human red blood cell membrane. The Journal of Biological Chemistry, 288(2), 848-858.

Ratanasopa, K., Strader, M. B., Alayash, A. I., \& Bulow, L. (2015). Dissection of the radical reactions linked to fetal hemoglobin reveals enhanced pseudoperoxidase activity. Frontiers in Physiology, 6, 39.

Reddi, A. R., \& Culotta, V. C. (2013). SOD1 integrates signals from oxygen and glucose to repress respiration. Cell, 152(1-2), 224-235.

Rifkind, J. M., \& Nagababu, E. (2013). Hemoglobin redox reactions and red blood cell aging. Antioxidants and Redox Signaling, 18(17), 2274-2283.

Rocha, S., Gomes, D., Lima, M., Bronze-da-Rocha, E., \& Santos-Silva, A. (2015). Peroxiredoxin 2, glutathione peroxidase, and catalase in the cytosol and membrane of erythrocytes under $\mathrm{H}_{2} \mathrm{O}_{2}$-induced oxidative stress. Free Radical Research, 49(8), 990-1003.

Rocha, S., Rocha-Pereira, P., Cleto, E., Ferreira, F., Belo, L., \& Santos-Silva, A. (2019). Linkage of typically cytosolic peroxidases to erythrocyte membrane A possible mechanism of protection in hereditary spherocytosis. Biochimica et Biophysica Acta (BBA) - Biomembranes, $1862(3), 183172$.

Sega, M. F., Chu, H., Christian, J. A., \& Low, P. S. (2015). Fluorescence assay of the interaction between hemoglobin and the cytoplasmic domain of erythrocyte membrane band 3. Blood Cells, Molecules, and Diseases, 55(3), 266-271.

Sidorenko, S. V., Ziganshin, R. H., Luneva, O. G., Deev, L. I., Alekseeva, N. V., Maksimov, G. V., \& Orlov, S. N. (2018). Proteomics-based identification of hypoxia-sensitive membrane-bound proteins in rat erythrocytes. Journal of Proteomics, 184, 25-33.

Sirota, T. V. (1999). Novyj podhod $\mathrm{v}$ issledovanii processa autookislenija adrenalina ispol'zovanie ego dlja izmerenija aktivnosti superoksiddismutazy [A new approach to the investigation of adrenaline autooxidation and its application for determination of superoxide dismutase activity]. Voprosy Medicinskoj Himii, 45(3), 263-272 (in Russian).

Taradina, G. V., \& Dotsenko, O. I. (2011). Oligomernye intermediaty katalazy v rastvore pri dejstvii nizkochastotnoj vibracii [Oligomeric intermediates of catalases in a solution at influence of low-frequency vibration]. Problems of Ecology and Nature Protection of Techogen Region, 11, 323-329 (in Russian).

Tharaux, P.-L. (2019). Posttranslational modifications of sickle hemoglobin in microparticles may promote injury. Kidney International, 95(6), 1289-1291.

Tiwari, M. K., Hägglund, P. M., Møller, I. M., Davies, M. J., \& Bjerrum, M. J. (2019). Copper ion $/ \mathrm{H}_{2} \mathrm{O}_{2}$ oxidation of $\mathrm{Cu} / \mathrm{Zn}$-superoxide dismutase: Implications for enzymatic activity and antioxidant action. Redox Biology, 26, 101262.

Tu, H., Wang, Y., Li, H., Brinster, L. R., \& Levine, M. (2017). Chemical transport knockout for oxidized vitamin $\mathrm{C}$, dehydroascorbic acid, reveals its functions in vivo. EBioMedicine, 23, 125-135.

Ugurel, E., Piskin, S., Aksu, A. C., Eser, A., \& Yalcin, O. (2020). From experiments to simulation: Shear-induced responses of red blood cells to different oxygen saturation levels. Frontiers in Physiology, 10, 1559

Wang, C. C., Tao, M., Wei, T., \& Low, P. S. (1997). Identification of the major casein kinase I phosphorylation sites on erythrocyte band 3. Blood, 89(8), 3019-3024. 
Wang, Y., Branicky, R., Noë, A., \& Hekimi, S. (2018). Superoxide dismutases: Dua roles in controlling ROS damage and regulating ROS signaling. The Journal of Cell Biology, 217(6), 1915-1928.

Welbourn, E. M., Wilson, M. T., Yusof, A., Metodiev, M. V., \& Cooper, C. E. (2017). The mechanism of formation, structure and physiological relevance of covalent hemoglobin attachment to the erythrocyte membrane. Free Radical Biology and Medicine, 103, 95-106.

Wolff, S. P. (1994). Ferrous ion oxidation in presence of ferric ion indicator xylenol orange for measurement of hydroperoxides. Methods in Enzymology, 233, 182-189.
Wolff, S. P., \& Dean, R. T. (1987). Monosaccharide autoxidation: A potential source of oxidative stress in diabetes? Bioelectrochemistry and Bioenergetics, 18, 283-293.

Zhou, S., Giannetto, M., DeCourcey, J., Kang, H., Kang, N., Li, Y., Zheng, S., Zhao, H., Simmons, W. R., Wei, H. S., Bodine, D. M., Low, P. S., Nedergaard, M., \& Wan, J. (2019). Oxygen tension-mediated erythrocyte membrane interactions regulate cerebral capillary hyperemia. Science Advances, 5(5), eaaw4466. 